Rakenteiden Mekaniikka (Journal of Structural Mechanics)

Vol. 50, No 3, 2017, pp. 122-126

https://rakenteidenmekaniikka.journal.fi/index

https:/doi.org/10.23998/rm.64959

(c)Author(s) 2017.

Open access under CC BY-SA 4.0 license.

\title{
Probabilistic framework for product design optimization
}

\author{
Joni Keski-Rahkonen
}

Summary. Probabilistic methods have gradually gained ground within engineering practices but currently it is still the industry standard to use deterministic safety margin approaches to dimensioning components and qualitative methods to manage product risks. These methods are suitable for baseline design work but quantitative risk management and product reliability optimization require more advanced predictive approaches. Ample research has been published on how to predict failure probabilities for mechanical components and furthermore to optimize reliability through life cycle cost analysis. This paper reviews the literature for existing methods and tries to harness their best features and simplify the process to be applicable in practical engineering work. Recommended process applies Monte Carlo method on top of load-resistance models to estimate failure probabilities. Furthermore, it adds on existing literature by introducing a practical framework to use probabilistic models in quantitative risk management and product life cycle costs optimization. Our main focus is on mechanical failure modes due to the welldeveloped methods used to predict these types of failures. However, the same framework can be applied on any type of failure mode as long as predictive models can be developed.

Key words: probabilistic models, product reliability, risk management, life cycle costs, structural optimization

Received 17 June 2017. Accepted 6 July 2017. Published online 21.8.2017.

\section{Description}

In engineering it still appears to be an industry standard to handle product design with deterministic models and risk management with qualitative tools [3], [19], [9], [6]. This is rather surprising considering quantitative probabilistic methods are widely in use in many other fields such as finance and insurance [8]. Such methods have also been introduced to engineering applications more than 50 years ago [5]. In addition, little research exists to show the actual performance of traditional qualitative risk management methods [8], [2]. On the contrary, literature suggests that even simple quantitative models beat expert judgement at prediction and decision making within many practical applications [22] [12]. While the performance of qualitative risk management methods remains uncertain in the light of scientific research, there is evidence showing the superiority of quantitative methods [8], [15], [1]. Based on the trend seen in other fields and based on the literature on performance comparisons it appears reasonable to work 
towards implementing probabilistic quantitative methods in engineering practices as well. It is to be noted, however, that these methods should be simple enough to be practical.

The reliability level to which a certain product should be designed, is a common topic of debate. One party often prefers to drive manufacturing costs down, while the other argues for higher reliability. From a financial perspective, this debate boils down to a product life cycle costs optimization. In other words, there should be a reliability level that optimizes the trade-off between manufacturing and quality costs, which realize in cases of failure. The idea of optimizing risk exposure in terms of costs within the design is not a new one. The literature introduces four general methods to analyze engineering decisions: Life Cycle Cost Analysis (LCCA), Utility Theory (UT), Cumulative Prospect Theory (CPT) and Life Profitability Method (LPM) [7]. UT \& CPT try to incorporate the risk preferences of the true decision maker into the objective function while LCCA is based on the financial value only [7], [13], [18]. LPM is a version of LCCA, capturing more financial information by covering positive cash flows as well [7]. We sympathize with the idea of trying to incorporate cognitive biases into decision analysis tool to have the optimizer to be in line with a true human decision maker. That makes perfect sense if the purpose of the model is to mimic a human decision maker. However, we concentrate on models which are financially rational, have the potential to differ from actual human opinion and aid in making better decisions. That leaves UT and CPT out of our interest. Another argument against UT, CPT and LPM is their added layer of complexity compared to LCCA. LCCA methods are simpler since they do not require decision maker specific parameters. Decision maker and application specific risk tolerances can be implemented simply as an optimization constraint while keeping the optimization process itself as a constant.

Several LCCA approaches have been suggested [11], [10], [17], [16], [4], [14]. This paper introduces an alternative LCCA framework, which pursues a simpler and more practical approach to tackle the reliability optimization in everyday engineering work, while not sacrificing too much prediction accuracy. In order to define the process, we apply well-established engineering practices but also borrow from probability theory, financial models and decision analysis.

This paper provides a framework on which to define risk levels while striving to maximize product cost-effectiveness. This is achieved by applying optimization techniques on financial risk exposure, while considering design and legal requirements as well as environmental and safety risks as constraints. First, the process is performed on component level and then the component results are extended to the system level. The introduced probabilistic design process can be expressed as steps shown in table 1.

\section{Failure probability and life cycle costs}

In order to predict the failure probability of a component, a mathematical model is required. Material mechanical failure models are well-developed and quite accurate, therefore we concentrate on them within the scope of this paper. Figure 1 shows a typical process flow chart for solving component failure probability in case of mechanical failure modes.

In order to reduce computation time it is preferable to seek for procedures where the Monte Carlo iteration loop is a post-processing step for finite element method (FEM). 
Table 1. Process steps for probabilistic design framework.

\begin{tabular}{cl}
\hline Step number & \\
\hline 1 & Apply a model to predict the failure probability for component design options \\
2 & Calculate expected life cycle costs for component design options \\
3 & Consider constraints to define acceptable design space \\
4 & Choose acceptable design with the lowest expected life cycle costs \\
5 & $\begin{array}{l}\text { Repeat the process for all the components of the system and verify the risks } \\
\text { on the system level }\end{array}$ \\
\hline
\end{tabular}

Fortunately, the stress distribution for practical strength related problems can be often solved with reasonable accuracy by applying linear FEM. Findley criterion is generally a good choice as a multiaxial fatigue failure criterion for steel materials [20], [21].

Capability to solve the failure probability of a component has applications not only on risk management but also on minimizing product life cycle costs. In efficient markets the product with lower life cycle costs will have a competitive edge, all else being equal. Therefore, the exercise of minimizing life cycle costs can also be seen as a process of maximizing the customer value of a product having certain given features.

Following Gardoni et.al. we define the expected life cycle costs $E[L(f)]$ as a sum of expected manufacturing cost $E[M(f)]$, discounted expected quality costs $E[Q(f)]$ and discounted expected life maintenance costs $E[C]$ according to equation [7]

$$
E[L(f)]=E[Q(f)]+E[M(f)]+E[C] .
$$

Since $E[C]$ is not a function of failure probability $f$, it can be set to zero while having no impact on the optimization result in terms of $f[14]$.

By manufacturing costs, we refer to all the costs such as material and work that are due to the manufacturing and design process of a component. After applying methodology shown in figure 1 to solve failure probability, it is also a straightforward practice to estimate manufacturing costs for a component design option based on historical data of manufacturing similar components. Estimation of the two quantities for several design options allows to curve fit a function for expected manufacturing costs $E[M(f)] . E[M(f)]$ has a downward sloping shape due to the practical reason that typically the cheaper structural design is not as reliable (1- $f$ ) as the more expensive one. Obviously, there is no reason to mathematically study design details that increase reliability but have no adverse effect on manufacturing costs. These are no-brainers and design optimization techniques are not required.

Quality costs $Q_{i}$ can be estimated based on historical data, and as we define them, they only realize in case of failure. Therefore, we should be interested in expected quality costs $E[Q(f)]$ which is a product of the probability of failure $f$ and the cost of failure $Q_{i}$ discounted to the same time period with $E[M(f)]$. Since $Q_{i}$ is a constant for a certain failure mode of a component, $E[Q(f)]$ always has an upward sloping shape. 
The objective function $E[L(f)]$ is a sum of a downward sloping and an upward sloping function. For that reason within all practical problems $E[L(f)]$ has a parabolic shape as shown in figure 2. The actual formula of the objective function is case specific and therefore the figure 2 is only indicative. Rather, the essential fact is that on a free optimization case the minimum of the parabola is an optimal reliability level in terms of discounted life cycle costs. Risk management, legal constraints and all the other design requirements can be taken into account as constraints for the optimization problem. The optimal choice is a feasible and acceptable design with the lowest life cycle costs.

Following the procedure shown in figure 1, Rolls-Royce has developed an in-house code that solves failure probabilities for mechanical failure modes in order to improve quantitative risk management within structural design process. The introduced probabilistic design methodology is also applied to ensure competiveness of the products.

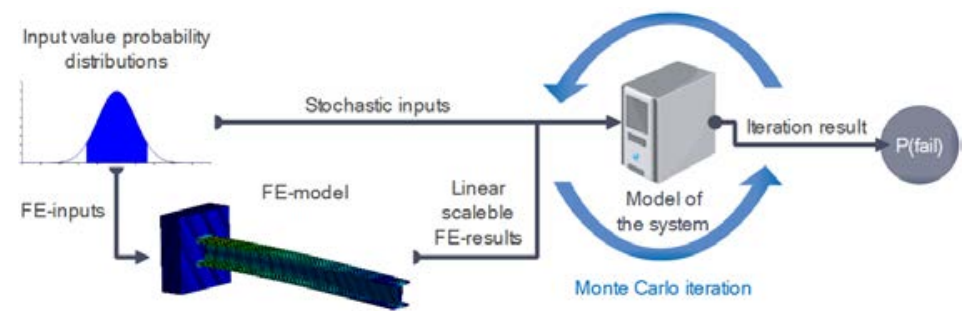

Figure 1. Process flow chart on solving failure probability.

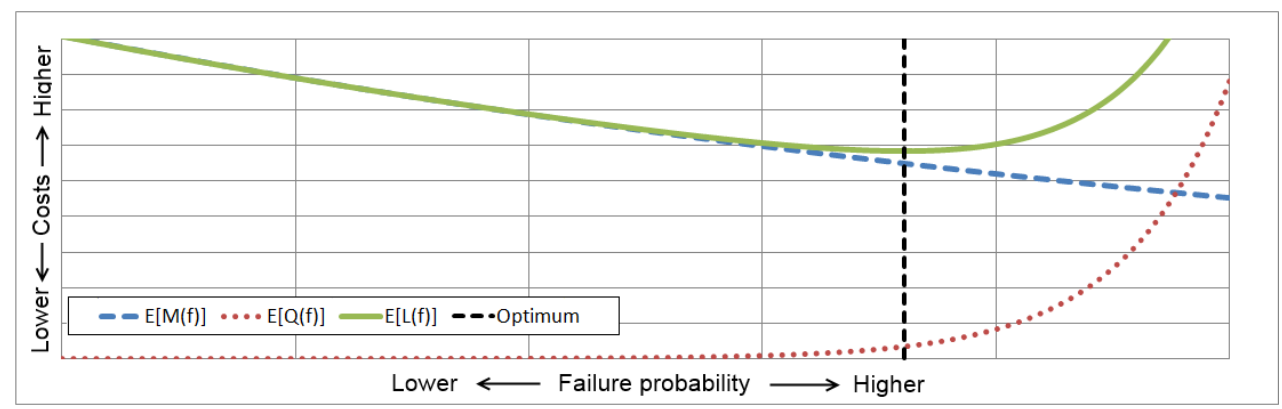

Figure 2. Life cycle cost function.

\section{References}

[1] L. B. Chincarini, A Comparison of Quantitative and Qualitative Hedge Funds, 2010.

[2] L. A. Cox, "What's wrong with risk matrices?," Risk Analysis, pp. 497-512, 2008.

[3] DNVGL-CG-0138, Direct strength analysis of hull structures in passenger ships, 2016.

[4] Dan M. Frangopol, Kai-Yung Lin, and Allen C. Estes, "Life-Cycle Cost Design of Deteriorating Structures," Journal of Structural Engineering, vol. 123, no. 10, pp. 1390401, 1997. https://doi.org/10.1061/(ASCE)0733-9445(1997)123:10(1390)

[5] A. M. Freudenthal, J. M. Garrelts, and M. Shinozuka, "The Analysis of Structural Safety," Journal of the Structural Division, pp. 267-325, 1966.

[6] P. Gardoni, A. Der Kiureghian, and K. Mosalam, "Probabilistic capacity models and fragility estimates for reinforced concrete columns based on experimental observations," Journal of Engineering Mechanics, vol. 128, no. 10, pp. 1024-38, 2002. https://doi.org/10.1061/(ASCE)0733-9399(2002)128:10(1024) 
[7] Paolo Gardoni, Fausto Guevara-Lopez, and Alessandro Contento, "The Life Profitability Method (LPM): A financial approach to engineering decisions," Structural Safety, vol. 63, pp. 11-20, 2016. https://doi.org/10.1016/j.strusafe.2016.06.006

[8] D. W. Hubbard, The Failure of Risk Management: Why It's Broken and How to Fix It.: Wiley, 2009.

[9] R. Jerrard, R. N. Barnes, and A. Reid, "Design, risk and new product development in five small creative companies," International Journal of Design, pp. 21-30, 2008.

[10] Joint Committee of Structural Safety, "Reliability Based Code Calibration," 2002.

[11] Joint Committee of Structural Safety, "Risk Assessment in Engineering," Principles, System Representation \& Risk Criteria, 2008.

[12] Daniel Kahneman, Thinking, Fast and Slow.: Farrar, Straus and Giroux, 2011.

[13] Daniel Kahneman and Amos Tversky, "Prospect Theory: An Analysis of Decision under Risk," Econometrica, vol. 47, pp. 263-291, 1979. https://doi.org/10.2307/1914185

[14] R. Kumar, P. Gardoni, and M. Sanches-Silva, "Effect of cumulative seismic damage and corrosion on life-cycle cost of reinforced concrete bridges," Journal of Earthquake Engineering \& Structural Dynamics, vol. 38, no. 7, pp. 887-905, 2009. https://doi.org/10.1002/eqe.873

[15] F. Macmillan, Risk, Uncertainty and Investment Decision-Making in the Upstream Oil and Gas Industry, 2000.

[16] "Minimum building life-cycle cost design criteria I methodology and II applications," Journal of Structural Engineering, vol. 127, no. 3, 2001.

[17] J. S. Nathwani, N. C. Lind, and M. D. Pandey, "Affordable Safety By Choice: The Life Quality Method," 1997.

[18] John von Neumann, Oskar Morgenstern, Harold William Kuhn, and Ariel Rubinstein, Theory of games and economic Behavior.: Princeton University Press, 2007.

[19] Josef Oehmen, Mohammad Ben-Daya, Warren Seering, and Muhammad Al-Salamah, "Risk Management in Product Design: Current State, Conceptual Model and Future Research," in ASME 2010 International Design Engineering Technical Conference, Montreal, 2010. https://doi.org/10.1115/DETC2010-28539

[20] Roger Rabb, Todennäköisyysteoriaan pohjautuva väsymisanalyysi.: Books on Demand, 2014.

[21] Roger Rabb, Christian Lönnqvist, and Jan Kaas, "Multiaxial Fatigue Criteria Applied to Medium Speed Diesel Engines," in ICMFF9, Parma, 2010.

[22] Amos Tversky and Daniel Kahneman, "Judgement under Uncertainty: Heuristics and Biases," Science, vol. 185, pp. 1124-1131, 1974. https://doi.org/10.1126/science.185.4157.1124

Joni Keski-Rahkonen

Rolls-Royce Oy Ab

PL 220, 26101 Rauma

joni.keski-rahkonen@rolls-royce.com 